\title{
Osteopathic research: Where have we been and where are we going?
}

Although the colleges of osteopathic medicine (COMs) and their teaching hospitals are often criticized for emphasizing teaching and clinical service at the expense of research, actually an impressive research record has been emanating from these institutions. The growing list of research abstracts and papers presented at the annual AOA research conference and published in the JAOA (see July through October issues) is evidence of this fact.

As the number of COMs, most of which are university-affiliated and publicly funded, tripled during the $1970 \mathrm{~s}$, so too did the volume of original research. But as Irvin M. Korr, PhD, writes in his article beginning on page 156, "There has been little increase of research, however, in areas most relevant to osteopathic theory and practice, and designed to test and refine the theory and improve the effectiveness of practice."

It is precisely this point that deserves widespread discussion and action. Dr Korr contends that research in areas most relevant to osteopathic theory and practice requires a shift from the "reductionist" paradigm to a "holistic" paradigm. The reductionist approach to biomedical research has resulted in important discoveries but is incomplete, according to Dr Korr. Specifically, the reductionist paradigm "regards the organism-the person-as merely the sum of body parts....[it] fails to see that when illness occurs, whatever the affected part, it is illness of the person."

One of our important responsibilities as a health profession is to meet the challenge of describing, defining, and studying osteopathic theory and practice. For too long we have abdicated our responsibility to advance the science on which our osteopathic medical education and practice is based.

Professor Korr describes a new, more complete approach to research. As such, the deans of the COMs will use Dr Korr's article to educate and orientate faculty as well as to stimulate the development of needed research. This article will also serve as a reference for osteopathic academicians as they accept the responsibility of familiarizing research- ers with the questions concerning osteopathic medicine and those available resources that may lead to answers.

Faculty research scientists will find Professor Korr's interpretation of osteopathic principles stimulating and succinct. His jargonless descriptions and referenced research conclusions make for welcomed reading this New Year.

THOMAS WESLEY ALLEN, DO Editor in Chief

\section{$J A O A$ to feature laboratory medicine update series}

Changes, updates, and advances in the field of laboratory medicine seem to occur on almost a daily basis. Familiarity with these advances is important not only to hospital-based physicians but to office-based primary care physicians as well.

Beginning on page 177 in this issue, The Journal begins a series of articles, directed at the primary care physician, detailing various aspects of laboratory medicine. Among the topics that will be covered are glucose monitoring and technology for home use; automatic hematology data; office laboratory equipment for the family practitioner; blood alcohol testing; laboratory statistics, sensitivities, specificities, and predicted values; and an update on current testing for hepatitis. John Fernandes, DO, chairman of the Department of Pathology and Laboratory Medicine at the Philadelphia College of Osteopathic Medicine, is the contributing editor of this series.

The series will appear monthly in the Clinical Practice section of the JAOA. As always, we welcome your comments and suggestions.

THOMAS WESLEY ALLEN, DO Editor in Chief 